\title{
Culture, Politics, and Development
}

\section{Faculty Research Working Paper Series}

\section{Michael Woolcock}

Harvard Kennedy School

\section{September 2014 RWP14-041}

Visit the HKS Faculty Research Working Paper Series at:

http://web.hks.harvard.edu/publications

The views expressed in the HKS Faculty Research Working Paper Series are those of the author(s) and do not necessarily reflect those of the John F. Kennedy School of Government or of Harvard University. Faculty Research Working Papers have not undergone formal review and approval. Such papers are included in this series to elicit feedback and to encourage debate on important public policy challenges. Copyright belongs to the author(s). Papers may be downloaded for personal use only. 


\title{
Policy Research Working Paper 6939
}

\section{Culture, Politics, and Development}

\author{
Michael Woolcock
}

The World Bank

Development Research Group

Poverty and Inequality Team

June 2014 
Policy Research Working Paper 6939

\begin{abstract}
Whether in the domains of scholarship or practice, important advances have been made in recent years in our understanding of how culture, politics, and development interact. Today's leading theorists of culture and development represent a fourth distinctive perspective vis-à-vis their predecessors, one that seeks to provide an empirically grounded, mechanisms-based account of how symbols, frames, identities, and narratives are deployed as part of a broader repertoire of cultural "tools" connecting structure and agency. A central virtue of this approach is less the broad policy prescriptions to which it gives riseindeed, to offer such prescriptions would be something of
\end{abstract}

a contradiction in terms - than the emphasis it places on making intensive and extensive commitments to engaging with the idiosyncrasies of local contexts. Deep knowledge of contextual realities can contribute constructively to development policy by enabling careful intra-country comparisons to be made of the conditions under which variable responses to otherwise similar problems emerge. Such knowledge is also important for discerning the generalizability (or "external validity") of claims regarding the efficacy of development interventions, especially those overtly engaging with social, legal, and political issues.

This paper is a product of the Poverty and Inequality Team, Development Research Group. It is part of a larger effort by the World Bank to provide open access to its research and make a contribution to development policy discussions around the world. Policy Research Working Papers are also posted on the Web at http://econ.worldbank.org. The author may be contacted at mwoolcock@worldbank.org.

The Policy Research Working Paper Series disseminates the findings of work in progress to encourage the exchange of ideas about development issues. An objective of the series is to get the findings out quickly, even if the presentations are less than fully polished. The papers carry the names of the authors and should be cited accordingly. The findings, interpretations, and conclusions expressed in this paper are entirely those of the authors. They do not necessarily represent the views of the International Bank for Reconstruction and Development/World Bank and its affiliated organizations, or those of the Executive Directors of the World Bank or the governments they represent. 


\title{
Culture, Politics, and Development
}

\author{
Michael Woolcock, World Bank ${ }^{1}$
}

Keywords: Culture, political development, context, identities, ethnicity

JEL code: Z13

\footnotetext{
${ }^{1}$ I am especially grateful to Deval Desai, Varun Gauri, Margaret Levi, Vijayendra Rao, Audrey Sacks and Caroline Sage for many years of fruitful discussions on these vexing topics.
} 
During the last twenty years a remarkable transformation has unfolded regarding the way in which culture is understood by scholars and practitioners of development. As recently as the early 1990s, discussions tended to oscillate around three views: culture was either irrelevant to development (in the sense of being un-actionable by prevailing policy instruments or derivative of more fundamental underlying economic and political structures); a 'problem' to be overcome by the adoption - forcibly, if necessary - of modern technologies and sensibilities (i.e., culture was a key repository of debilitating vestiges of 'backward traditions'); or a reified behavioral phenomenon aggregating to shape the wealth and poverty of nations (e.g., claims about the collective virtues and vices of "Asian values" in explaining the rise of East Asia and the stagnation of India). These three views and their legacies have far from disappeared, but today social scientists from a range of disciplinary backgrounds are deploying approaches that are at once more theoretically nuanced, more empirically grounded, and (as it happens) more useful in terms of both understanding development processes and constructively contributing to development strategies. While there is hardly a new consensus, there is broad agreement that culture is more fruitfully understood as context-specific sources of identity, aspiration and meaning, and as repertoires (i.e., an array of normative behavioral and political 'tools') that members of particular groups deploy to construct, navigate and make sense of their world.

Much remains to be learned, but these advances in theory and practice with regard to understanding culture constitute one of the most tangible and fruitful areas of inquiry in contemporary development research. Indeed, as important as these changes have been the ways in which, and the many and diverse sources from which, they have emerged. This paper seeks to provide a general overview of these transformations, the evidence on which they rest, their broader implications for engaging with the politics of development, and for development policy and practice. It does so with a particular focus on 'ethnicity', an issue which resides at the intersection of culture, politics and development in both the popular and scholarly imagination, but which has also been at the epicenter of recent theoretical and empirical research documenting the conditions under which culture becomes politically salient, and is deployed as part of broader behavioral repertoires of identity and sense-making. As such, I argue that culture does not merely comprise yet another set of "variables" that "matter" and which thus need to be "taken into account" when seeking to better understand and respond to the idiosyncrasies of particular times, places and circumstances; rather, more powerfully, it refers to our ongoing, historically 
contingent ways of making sense of the world, of discerning our place within it vis-à-vis other people and other groups, and of crafting specific strategies for survival and mobility. So understood, culture can be both an object of inquiry and an epistemological lens through which to examine some of the most important (but vexing) aspects of the human condition.

The paper is structured around four sections. Section I reviews the ways in which culture has been understood over the last sixty years (roughly corresponding to the period associated with the emergence of 'development' as a scholarly subject, global political project and professional field). Section II briefly surveys some of the most recent scholarship on culture as it pertains to politics and development, arguing that a qualitatively new approach is now gaining ascendance, with correspondingly significant implications for research and policy. Section III focuses on the subject of 'ethnicity', a long-standing and deeply contentious issue that demonstrates both the limitations of past approaches and the utility of emerging ones. Section IV concludes with a discussion of the implications of these analyses for development policy and practice, concluding with a call to appreciate the distinctive kinds of phenomena to which culture draws attention, and which careful cultural analysis can fruitfully illuminate.

\section{Goodbye to All That? Three Traditions of Culture and Their Discontents}

A discussion of recent contributions to the culture, politics and development literature is best understood by first considering three views that prevailed over the course of the late twentieth century, and how they rose to prominence and then (for the most part) declined (cf. Moore 1997).

As implied above, students of an earlier generation encountered rather contradictory views when pondering the relationship between culture and development. For many observers of development processes, and certainly for members of the dominant discipline in development (namely economics), culture - or, more accurately, "culture" - was at best epiphenomenal, a product of more fundamental underlying material or behavioral processes. Whether from the political left (Marxists focusing on class and inequality) or right (neoclassical researchers studying markets and market failures), economists could appreciate the existence of diverse tastes, preferences and aspirations around the world - made manifest in obviously different styles 
of music, dress, food, language and religion - and yet regard them as being of little consequence in shaping more primal structural forces driving economic development; far more likely, they presumed, the causal arrow went in the opposite direction. Moreover, since any rendering of "culture" was inherently difficult to measure and model, and gave rise to responses that mapped awkwardly if at all onto policy instruments, it was readily consigned to the intellectual and status periphery; upon even hearing the word 'culture' in scholarly circles, economists were likely to join playwright Hanns Johst in "reaching for their gun."2

Not all social scientists held such dismissive views, however. At the other end of the enthusiasm scale, culture came to prominence in two different strands of work in development, one focused on 'micro' issues - families and communities - and the other on more 'macro' concerns - broad changes within and between societies. ${ }^{3}$ At the micro level, perhaps the most durable rendering of culture in the mid-twentieth century was the work of Oscar Lewis (1959), whose detailed study of five marginalized communities in Mexico led him to argue that such communities were characterized by a "culture of poverty", namely self-reinforcing and multigenerational cycles of disadvantage in which certain behaviors (teen pregnancy, school truancy) and attitudes (tardiness, profligacy) conspired to reduce the likelihood that the poor could or would escape their unfortunate circumstances. ${ }^{4}$ Since its first appearance, variations on this expression have been appropriated by critics of the welfare state (e.g., Murray 1994) - as were earlier manifestations by Thomas Malthus and other critics of the English Poor Laws more than two hundred years ago - to popularize the notion that poverty is primarily a function of, indeed caused by, 'dysfunctional' individual attitudes and behaviors, and that these are only perpetuated and consolidated by transfers ('handouts') from the state. ${ }^{5}$ As we shall see, the most recent

\footnotetext{
${ }^{2}$ Variations on this line have been used in many contexts, but as written it appears to have been first deployed in Schlageter, a play by Hanns Johst first performed in Germany in the 1930s. (This unfortunate historical fact has clearly not diminished its value as a one-line witticism.)

${ }^{3}$ For present purposes, I do not discuss the intellectual or scholarly underpinnings informing the work of agencies such as UNESCO whose work focuses on preserving a country's "cultural heritage" (understood to be ancient or historically significant artifacts, buildings, sacred sites or artistic endeavors).

${ }^{4}$ For a specific critique of the "culture of poverty" thesis, see Goode and Eames (1996) and Mohan (2011).

${ }^{5}$ Needless to say, this line of argument has had its vehement critics along the way. Szreter (2007), for example, drawing on a range of careful studies in recent years by economic and social historians, argues that the presence of the Poor Laws (and associated civic innovations such as widespread identity registration) freed up capital and labor from its Feudal bounds and ensured that the risks of experimentation (in the realms of technology, ideas or challenges to elite authority) did not include unmitigated destitution. The advent of these new and distinctive arrangements, he maintains, at least partially explains how Britain, an economically backward country in 1500 vis-àvis other European powers (especially the Dutch) when the Poor Laws were first introduced, embarked - albeit
} 
scholarship on these issues has sought to articulate ways of incorporating cultural sensibilities into more widely shared understandings of 'poverty traps' in which structures and agency jointly contribute to the making and breaking of reinforcing cycles of disadvantage.

The more 'macro' wing of the "cultural explanations" school of political development emerged in the 1960s and 1970s as part of the broader corpus of influential ideas known as modernization theory, particularly as manifest in the classic work of Almond and Verba (1963) and Inkeles (1975). Modernization theories linked culture to an array of different 'values' (e.g., gender norms, reproductive rights, individualism) associated with secular transitions from 'traditional' to 'modern' (and perhaps 'postmodern') society, a line of research continued in the work of Ronald Inglehart (e.g., Inglehart 1997, Inglehart and Welzel 2005) and others interrogating longitudinal data compiled by the World Value Survey. The core thesis of modernization theory was that transitions in economic, political, and social life occurred sequentially and predictably (if not always at the same pace), and that as countries become more 'modern' these transitions would yield incremental institutional and behavioral convergence. In its time, modernization theory derived its intellectual force from the fact that both the political left and right ascribed to this teleology; Marxists merely assumed that history's arc would inexorably reveal that there was another destination further down the line from capitalism (namely communism).

In this space, culture gained its policy salience because it was regarded as either a bellweather or laggard indicator: taking the pulse of a country's "cultural values" through large-scale surveys could provide a guide as to how far along the modernization track that country (and/or its various constituent social groups) had come, even as it was recognized that cultural change itself was likely to follow a "lumpy" trajectory, with 'beliefs' and 'attitudes' often out of sync with prevailing institutions or revealing potentially sharp divisions between groups (whether defined demographically or geographically) who were themselves at different points in their journey to modernity (e.g., with regards to views regarding the status of minority groups or women). From this perspective, the modernization process remains everywhere incomplete; wealthy countries, no less than developing countries, continue to wrestle with these dynamics, as 
the deep contention accompanying issues such as gay rights and immigration during national election campaigns amply demonstrates.

The most popular and widely cited ${ }^{6}$ works of the "cultural explanations" school came at the end of the twentieth century. Explicitly invoking the mantle of Max Weber's classic thesis linking the Protestant ethic to the emergent "spirit" of capitalism in the aftermath of the Reformation, three books - Samuel Huntington's (1996) infamous Clash of Civilizations, David Landes's (1999) The Wealth and Poverty of Nations and Lawrence Harrison and Huntington's (2001) edited volume Culture Matters - sought to argue that similar processes were at work today. For these authors, the driving force was not just a specific behavioral mechanism (of the kind identified by Weber - where pervasive anxiety about one's uncertain fate in the afterlife was seen to have unwittingly put in motion, in the present life, a virtuous cycle of thrift, diligence, self-restraint and investment ${ }^{7}$ ) but, in effect, an entire assemblage of attitudes, 'values' and dispositions residing at the national, even regional, level. In these works, culture was now elevated to the status of an independent actor (nee, a bona fide independent variable) shaping a country's, even an entire civilization's, development prospects. This simplistic thesis was eagerly embraced by populist pundits, who readily connected it to earlier claims about the role of "Asian values" in explaining the rise of the East Asian 'miracle' economies (the Republic of Korea; Taiwan, China; Singapore) and laments that the "Hindu rate of growth" accounted for the (then) sluggish performance of India.

Echoes of all three of these perspectives endure ${ }^{8}$, but where once - whether by design or default - they constituted the epicenter of debate about the role of culture and development they now, in the second decade of the twenty-first century, seem far removed from it, at least in what currently constitutes the 'cutting edge' of scholarship on poverty, politics and development. It is perhaps too soon to offer a compelling explanation of how and why the influence of all three

\footnotetext{
${ }^{6}$ As of this writing, according to Google Scholar, Huntington (1996) has over 11,500 citations, Landes (2000) has over 3,500 citations and Harrison and Huntington (2001) has more than 1000 citations. These are high counts by any estimation, but especially so for works on culture and development.

${ }^{7}$ The Protestant Ethic was one of Weber's first scholarly efforts, but as Richard Swedberg has astutely noted, it was not one that Weber himself seemed to warmly embrace as his writing matured; he rarely cited it in the more voluminous works (Economy and Society, General Economic History) written in his later years.

${ }^{8}$ Witness, for example, the wide array of emotive responses elicited by Yale law professor Amy Chua's (2011) popular book Battle Hymn of the Tiger Mother, in which the public debate centered on the virtues and vices of the 'Asian values' allegedly driving Asian parents' seemingly intense child-rearing practices, not least among Asians now living in the West.
} 
approaches receded and were replaced by a new one (see below), but at least two plausible factors can be cited. First, the earlier perspectives reflected the sensibilities of an age that has passed. Modernization theory, ostensibly a product of the Cold War but a descendent of ideas informing (and justifying) nineteenth and early twentieth century colonialism, long ago lost its scholarly traction; many now readily appreciate 'modernization' as an ongoing historical fact and process without necessarily buying into the singular ideological and teleological assumptions of modernization theory, and the policy imperatives to which it gave rise (Woolcock 2009). Similarly, discussions about cross-national shifts in "values" and "beliefs", while notionally important to document, obscure the more vibrant and salient ways in which the politics of these dynamics play out across multiple sub-national units and between different social groups (themselves often a fluid category; see below). More practically, beyond a certain point reifying culture to the status of an independent variable at the national (or "civilizational") level proved to be neither intellectually interesting nor in any way useful for policy purposes (Rao and Walton 2004); at best it might generate an opening for a more serious conversation about culture, but at worst it could reinforce unhelpful stereotypes, undermine the space for agency (e.g., political leadership, civic deliberation, individual and collective choice) and for opportunities to identify how, where and by whom hybrid identities and institutions were being forged, as they have been in the past (see Bayly 2004).

The second factor shaping the demise of these older perspectives was the emergence of a serious rival grounded in a richer and more nuanced vein of theory and evidence. In the early 2000s, for whatever reason - perhaps because of their frustration with the prevailing tone and terms of debate - sociologists, historians, and anthropologists not only reengaged with culture and development, producing a string of insightful and compelling works, but also began actively contributing to policy deliberations. Equally importantly for development policy purposes, some economists also launched a minor revolution of their own, revisiting some of the first principles of their discipline (e.g., rationality, self-interest, utility maximization as human universals) via micro-behavioral experimental research in different contextual settings (Henreich et al 2004 being the most famous; see also Henreich at al 2011). It is to a discussion of this emerging literature that we now turn. 


\section{Taking Context Seriously: Recent Interdisciplinary Contributions}

Cultural anthropology has long sought to focus cultural analyses on the role of symbols and meaning, but it was the classic article of Swidler (1986) that both refined this approach and brought it into the mainstream of social and political theory, from whence it began to be fruitfully applied to poverty research and development policy in the 1990s. ${ }^{9}$ Swidler's central argument was that "[c]ulture influences action not by providing the ultimate values toward which action is oriented, but by shaping a repertoire or 'tool kit' of habits, skills, and styles from which people construct 'strategies of action'” (p. 273); moreover, she sought to show that culture's causal role in shaping social life varied according to the extent to which a particular historical moment was culturally "settled" or in a period of flux. The notion of culture as a repertoire provided a novel analytical entry point for examining how social structures, group norms particularly as it pertained to source of status, honor and meaning - and individual choices conjoined to generate patterns of behavior ${ }^{10}$, some of which were remarkably consistent across time and space and yet also often highly variable within demographic groups ('Asians', 'African Americans', 'Armenians') heretofore deemed to be the more 'natural' or 'primary' locus of cultural dispositions. Such groups may indeed be repositories of culture in the popular sense (Davis 2009), but the conceptual innovation pioneered by Swidler was to understand culture as a mechanisms-based phenomenon rooted in shared capacities to create and exchange symbols as part of broader processes of meaning, strategic behavior and inter/intra- group differentiation (Wadeen 2002). Indeed, it can be argued that groups of any kind cannot act collectively unless and until such fundamental issues are resolved (see Gauri et al 2013).

As we shall see below, an explosion of research on ethnicity - an issue made politically salient in the early 1990s with the end of communism and the descent of many post-socialist states into violence popularly construed to be grounded in and/or driven by long-standing 'ethnic' grievance - and communal conflict helped both to exemplify and consolidate this new approach to culture in mainstream social science. Beyond the research on ethnicity, however, a

\footnotetext{
${ }^{9}$ Swidler's work, in turn, extended the earlier and contemporaneous (and even more broadly influential) work of French social theorist Pierre Bourdieu.

${ }^{10}$ It proved especially useful for explaining behaviors such as teen pregnancy, gang violence, and common pool resource management, which were problematic for standard rational choice models focused on the self-interested, utility-maximizing individual agent.
} 
rich heritage of qualitative inquiry, especially of urban poverty, was also revived. Encapsulated in important contributions by (among others) Michele Lamont (2000) and Mario Small (2004), this work explored the ways in which particular social groups deployed group-specific narratives and narrative styles to regulate group boundaries - that is, to determine who is and is not granted membership in a given group, and thus who is subject to what social rules (norms, expectations) regarding how status, shame, honor, and prestige is determined. ${ }^{11}$ An oft-cited example of these processes in action is the persistently high rates of teen pregnancy in poor, inner-city African American communities: where unemployment is rampant and where future economic prospects, especially for young men, are bleak, young women acquire status and attention as mothers indeed, their rite of passage to adulthood becomes marked not by graduation from high school or college but by child-bearing. ${ }^{12}$ Similar dynamics can be seen in the mechanisms by which 'durable inequalities' (Tilly 1999) persist across generations for particular social groups, and in poor communities in the developing world, wherein structured economic expectations and social identities coalesce to undermine what Appadurai (2004) calls 'the capacity to aspire' - the capacity to imagine an alternative life course and to believe that 'someone like me' can reasonably pursue it.

Related work in quantitative social science has been conducted in the US on what Claude Steele calls 'stereotype threat' (see Steele and Aronson 1995). In this research, two groups of randomly selected students from minority racial backgrounds are asked to perform a standardized test: one group is given no particular indication of what the test is for, while the other is told that it is a test of the intelligence of minority groups. In short, the only difference between the groups is that, in the latter, minority status is made public and thus politically salient. Students in the latter group, it turns out, typically perform worse on these tests than their identical peers in the 'non-salient' group, leading Steele to conclude that particular social markers matter, but only in social contexts where they are made to matter. Related research by economist Karla Hoff and her colleagues (see Hoff and Pandey 2006; Hoff et al 2011) find similar results on caste in India: young students asked to complete a simple maze perform poorly

\footnotetext{
${ }^{11}$ Small, Harding and Lamont (2010) provide an excellent summary of this evolving literature. See also Rao (2008) on the role of 'symbolic public goods' such as community associations and norms of civic participation in India and Indonesia as important cultural expressions.

12 See Patterson (2006) for a discussion of the comparable historical and cultural processes shaping the behavior of young men in many poor African American communities in the US.
} 
(compared to an otherwise identical group) when asked merely to publically identify themselves to their peers before completing the test; stating their name conveys their caste status to the group and thereby renders it salient as a social marker, with the students from the lower castes proceeding to exhibit cognitive performance consistent with broader societal perceptions of their inferior social status.

The collective upshot of this research is deep confirmation of the interplay of macro, meso and micro processes in shaping individual and collective behavior, and in particular in highlighting the distinctive role that culture - as repertoires, narratives and symbolic tools plays in connecting them. Far from celebrating or deploring 'culture' as a reified group characteristic, or dismissing it as an ethereal manifestation of more fundamental economic processes or interests, in this contemporary rendering culture is afforded a distinctive and central role in shaping the processes by which life is constructed, navigated and interpreted. It now draws its theoretical and empirical strength from across the social sciences, and while much remains to be learned and a shared consensus on all aspects (inherently) remains elusive, it is not unreasonable to assert that, over the last twenty five years, a veritable paradigm shift has taken place at the leading edge of research on culture, politics and development, and is now steadily consolidating itself as a fruitful basis for careful policy deliberations. Nowhere is this shift more evident that in the field of ethnicity.

\section{Rethinking Culture, Politics and Development in Action: The Case of 'Ethnicity'}

The role of ethnic diversity in understanding development outcomes (growth, poverty, inequality, effective governance, social cohesion) has a long but not always distinguished history. An early (and now 'classic') paper by Easterly and Levine (1997), for example, has garnered over 3,500 citations in the scholarly literature, but the field as a whole-despite expanding considerably across disciplinary lines and units of analysis (Brubaker 2009) - remains inherently contentious. Understanding the nature and extent of this scholarly contention can help to illuminate some of the corresponding challenges associated with applying this collective knowledge to development policy in regions such as Eastern Europe and Central Asia, where these issues have powerful political resonance and (thus) enduring consequences for development in generally and poverty reduction in particular (see Dudwick et al 2003). 
Efforts to interpret and respond in constructive ways to debates on the relationship between ethnic diversity, political dynamics and development outcomes face two perennial types of problems: measurement and theory. The measurement problems are relatively straightforward if the underlying assumption is that ethnicity and race are essentially fixed and coherent demographic categories. To be sure, there are likely to be legitimate concerns at the margins about how exactly to classify individuals with (say) a multi-racial heritage, how to compile data sets that are sufficiently comprehensive to adequately capture ethnic groups (however defined) who are geographically dispersed and/or small in number, and how to aggregate or compare seemingly similar categories (e.g., 'Jewish' ${ }^{13}$ ) across contexts. For the most part, however, these problems are familiar ones to survey researchers and an array of technical strategies exists for dealing with them; appropriate qualifiers will thus accompany the conclusions from such analyses. If their advice and recommendations are heeded, researchers may be granted more extensive resources, and in due course more precise estimates and finer-grained analyses will emerge. Such advances are to be welcomed and encouraged.

For a different group of social scientists, however, the key issue constraining policy options when engaging ethnic diversity is less methodological than theoretical (or, more precisely, ontological - What exactly is ethnicity, and for whom?). Specifically, these scholars hold that ethnicity is not necessarily a fixed demographic category readily measureable via household surveys but a fluid social construct, one whose political salience varies considerably across time, space and units of analysis, and one that is eminently amenable to manipulation (for better or worse) by social movements and civic leaders. In the scholarly literature this distinction (and ensuing debate) is usually referred to as one between 'primordialists' versus 'constructivists' (e.g., see Wimmer 2008). Varshney's (2001) study of communal violence in India represents an interesting (but rare) hybrid: he examined why certain urban areas with demographically similar ratios of Hindus and Muslims varied so widely in their propensity for violence, arguing that the key difference was their degree of joint membership in local civic

\footnotetext{
${ }^{13}$ Some Jews understand this label to be primarily an ethnic designation, others a religious one, still others a national one; some hold all three or some combination thereof. This creates obvious cross-context concerns when researchers or policymakers seek to know how many "Jewish" people there actually are in a broader regional (or global) space, and complicates discussions of what it "means" to be Jewish. Important distinctions can also be literally "lost in translation"; Benovil (2012), for examples, notes that "[t]he English word 'Russians' is not an exact translation of the original meaning. In Russian, there are two words: 'russkiye,' meaning ethnic Russians, and 'rossiyane,' meaning Russians as citizens of Russia. Both are translated as 'Russians' into English.”
} 
organizations. In areas where both Hindus and Muslims were members of the same business groups, for example, they knew each other at a personal level and were thus less amenable to inflammatory invective by partisan communal leaders, and better placed to anticipate (potential) and quickly resolve (actual) grievances. ${ }^{14}$

In methodological terms, 'constructivists' are more likely to regard ethnicity as a dependent (not independent) variable, i.e., a category that is a product of prevailing political processes rather than a determinant of them (see Jung 2008). The important work of Nicholas Dirks (2001), for example, on caste in India - popularly presumed to an enduring, immutable and defining feature of the sub-continent - shows that caste became politically salient in India only after the British began conducting national censuses which required respondents to be placed into fixed demographic categories (i.e., into "boxes", determined by the British themselves). What had once been relatively fluid and politically neutral thereby became, through modern instruments of "population management", relatively fixed and, in turn, a basis for political mobilization (and, concomitantly, social exclusion). A related thesis is posed in Anthony Marx's (1998) comparative analysis of the political salience of being "black" in South Africa, the United States, and Brazil: he argues that the highly variable status of "blackness" as a basis for political mobilization in these three countries is a product of the nature and extent to which the state itself is (or became) a site of political contestation around race. ${ }^{15}$ (Box 1 provides a simplified case study of these processes in Eastern Europe during the Soviet era.)

\footnotetext{
${ }^{14}$ See Jha (2007) for a related historical argument on the propensity for communal violence in coasting trading ports in colonial India. A 'constructionist' approach to understanding ethnicity is not only a staple of contemporary Western (Anglophone) scholarship; according to Benovil (2012) it has also become a hallmark of the most recent Russian literature, which argues in the main that the "borders of communities and changing and flexible, which makes an ethnic community based on existing relations, not based on existing objective characteristics." Historically, however, Soviet literature adopted a strongly primordialist approach (Tishkov 1997). The early Russian literature in particular often used the socio-biological term "ethnos" (which sought to classify ethnicities in ways analogous to zoological categories), though scholars today use it more to convey the sense that the bases of any given group's composition changes over time.

${ }_{15}$ Mamood Mamdani (1996) makes a similar historical argument for the processes by which "subjects" became "citizens" in late colonial Africa, as does Weber (1976) for the processes by which "peasants" became unified into "Frenchman" in late nineteenth/early twentieth century France.
} 


\section{Box 1: State-making and ethnicity in Eastern Europe}

It is a truism that, over the last twenty-five years, no region has experienced more tumultuous social, economic and political transformation that Eastern Europe and Central Asia. As has been the case with virtually every such transformation in earlier historical periods, and with the 'Arab Spring' today, the demise of the Soviet Union generated all manner of serious contention: it fundamentally altered, among many other things, relations between social groups (and with the state), expectations of job prospects and social security (health care, pensions, etc), and sources of authority, identity and power.

A distinctive feature of the post-Soviet experience was the political vacuum generated by the demise of a powerful central state, and the fact that that same state had itself, some seventy years earlier, in numerous instances created (by decree or brutal force) political entities - for the purposes of 'management' and control - where none had previously existed. In 1917 in what is now Turkmenistan, for example, Edgar (2004: 1-2) writes that there was no state, only "[a] seminomadic people...";

the Turkmen were fragmented into genealogically defined groups that spoke different dialects, were often at war with each other, and were ruled by at least five different states. The Turkmen population, overwhelmingly illiterate, was scattered over a huge and largely inaccessible expanse of arid terrain. Although these Turkmen groups claimed a common ancestry, they possessed no clearly bounded territory, no common political institutions, no uniform language, and no mass culture of print and education - in short, none of the trappings of modern statehood.

Where some have seen the Soviet Union has the "breaker" of nations, Edgar (2004) persuasively argues that it was instead - or at least in the case of Turkmenistan and others - a "maker" of nations. In any event, the key issue for present purposes is understanding the conditions under which "states" were formed during, and reformed following, the Soviet experience; transitional contention that is too readily construed as "ethnic" in nature or origin must first of all be examined in its historical and political context.

Thus, rather than studying the demographics of difference, these researchers examine what might be called the dynamics of difference; the key empirical question then becomes identifying the conditions under which particular aspects of people's identities can be mobilized for large-scale collective action (whether for constructive or harmful purposes). ${ }^{16}$ Where methodological problems (whether quantitative or qualitative) within the 'demographics' or

\footnotetext{
${ }^{16}$ Needless to say, this juxtaposition - between the demographics and the dynamics of difference - is perhaps overly simplified (indeed, students of ethnicity seem to revel in creating ever-finer distinctions when locating themselves in the theoretical landscape), but for present purposes it is a fruitful one for elucidating the key differences between (most) economists and (many) other social scientists studying ethnicity.
} 
'dynamics' tradition are concerned with measurement, sampling and inference, the theoretical differences on which these distinctions rest are embedded within more durable and discrete disciplinary divisions - which is to say, within traditions that are only partially amenable to reconciliation by garnering more and better 'evidence'. It is very important to understand these theoretical foundations, however, not only because any methodological choice is inherently embedded (knowingly or unknowingly, explicitly or implicitly) within a theory but because the logic of these different theories gives rise to different diagnoses (of "the problem") and thus different policy prescriptions (proposed "solutions"). ${ }^{17}$ So understood, even something as destructive as war is less axiomatically the 'result' of certain demographic configurations of 'ethnic diversity' but a process that can 'cause' (or even create) certain forms of social identity, such as 'ethnicity', and render politically (perhaps even militarily) salient social cleavages that were once neutral or irrelevant. As McGovern (2011: 352) astutely notes, numerous studies of the political anthropology of Africa demonstrate

that war tends to polarize identity and that even where there was a high degree of intercommunal cooperation and intermarriage, once wars begin, identities like ethnicity, religion, race, and nationality become salient as cycles of revenge, resentment, and demonization develop path-dependent rationales. But what of the poor multiethnic countries that don't experience war? What of Mali, Senegal, and Ghana? What of those countries in between, India or Guinea, that experience interethnic clashes, but manage them in such a way that they do not jump to the level of a more general conflagration? ... [A]nthropologists and political scientists have shown that there are infinitely many ways to construct competitive difference, from villages to clans to caste, just as every definition of enmity implies a related definition of alliance. In many African settings, ethnicity is epiphenomenal to the political dynamics that offer the conditions of possibility for its instrumentalization.

It is these dynamics, and their idiosyncratic manifestation in particular countries, that need to be explained for the purposes of inferring development policy and practice. ${ }^{18}$ Careful micro-level studies of the conditions under which 'ethnicity' is and is not able to be mobilized for the purposes of violence (e.g., Varshney 2002, Posner 2004, Kalivas 2006), as McGovern (2011: 350) also notes, "suggests that participants in violent politics are operating according to rational and irrational choice models at once. Such 'irrational choice' models must account for the presence and significance of actors' desires for respect, honor, adulation, and revenge." This is the importance sense in which contemporary theories of culture, as discussed above, are

\footnotetext{
${ }^{17}$ Put differently: to argue that "we don't need theory" is itself a theoretical statement.

${ }^{18}$ See also the similar arguments for assessing the significance of 'culture' for development policy and practice outlined in Rao and Walton (2004).
} 
gaining traction in debates about politics and development. They are at once able to provide an informed (even devastating) critique of culture and ethnicity understood as a discrete, static demographic phenomenon amenable to aggregate statistical analysis, and yet also able to provide a detailed empirical platform on which alternative theories, rigorous measures and actionable policy recommendations might be discerned. Such commitments to engaging with the idiosyncrasies of local contexts, and drawing on the large body of theory that inspires it, is, to quote McGovern (2011: 353) again,

neither a luxury nor the result of a kind of methodological altruism to be extended by the softhearted. It is, in purely positivist terms, the epistemological due diligence work required before one can talk meaningfully about other people's intentions, motivations, or desires. The risk in foregoing it is not simply that one might miss some of the local color of individual "cases." It is one of misrecognition. Analysis based on such misrecognition may mistake symptoms for causes, or two formally similar situations as being comparable despite their different etiologies. To extend the medical metaphor one step further, misdiagnosis is unfortunate, but a flawed prescription based on such a misrecognition can be deadly.

Even if, as is most likely, these contrasting approaches are ultimately complements rather than substitutes, there is no disputing that, over the last twenty years, theories emanating from the (non-economic) social sciences connecting culture, politics and development have themselves attained a distinct identity and growing self-confidence; it remains to be seen whether they are able to secure comparable influence shaping popular sentiments and, more importantly, policy debates in countries where such debates are most consequential.

\section{Conclusion}

The concept of culture is, and will forever be, contested, not only in the sense that it infamously has hundreds of different definitions (and counting), but that greater clarity will only emerge through deliberation rather than empirical refinement. But culture is no less important or useful for its necessarily contentious status; indeed, as with other "inherently contested concepts" (Galli 1956; Collier et al 2006) such as power and class, it does much of its intellectual work precisely through the quality of the deliberation it inspires. ${ }^{19}$ Beyond definitional debates, any rendering must be understood in the context of a broader theory, and it is at this level that genuine innovations have transpired over the last two decades. As this paper has hopefully demonstrated, today's leading social and political theorists of culture and development represent a fourth

\footnotetext{
${ }^{19}$ Woolcock (2010) makes a similar argument for understanding the debates accompanying 'social capital'.
} 
distinctive perspective vis-à-vis their predecessors, one that seeks to provide an empirically grounded, mechanisms-based account of how symbols, frames and narratives are deployed as part of a broader repertoire of cultural 'tools' connecting structure and agency.

A central virtue of this approach is less the broad policy prescriptions to which it gives rise - indeed, to offer such prescriptions would be something of a contradiction in terms - than the emphasis it places on making intensive and extensive commitments to engaging with, if not always fully understanding, the idiosyncrasies of local contexts (Barron et al 2011). Beyond familiar development bromides that "history and context matter", which are too often honored only in the breach, deep knowledge of contextual realities enables careful intra-country comparisons to be made, which can be a basis for identifying "positive outliers" - that is, places where vernacular solutions to otherwise divisive conflict has emerged. For example, if otherwise similar areas (demographically, economically, geographically) nonetheless have significantly different levels of 'ethnic conflict', it would surely be good to know how it is that residents of the 'low conflict' communities have managed to attain and sustain this welcome outcomes. Moreover, identifying and disseminating successful indigenous responses - as opposed to advocating the adoption of "best practice solutions" as determined by external "experts" - can imbue them with a powerful source of legitimacy. Forging detailed scholarly and experiential knowledge of local contexts is also important for discerning the generalizability (or 'external validity') of claims regarding the efficacy of policy interventions, especially those overtly engaging with 'social', 'legal' and 'cultural' issues in the least developed countries (see Woolcock 2013).

Whether in the domains of theory, research, policy or practice, important advances have been made in recent years in our understanding of how culture, politics and development interact. It is to be hoped that these gains will be consolidated, refined and enhanced in the years to come, on the basis of an ever-widening array of contributors. Finally, it bears repeating that culture is not merely an object of analysis, around which the contentious debates accompanying its definitions and metrics will eventually yield in the face of more brain power, expanded research budgets or larger data sets; culture is one of the defining features of what it means to be human, and as such central aspects of it must remain not only "inherently contentious" but 
forever elusive. Cultural analyses should help us to appreciate the distinctive kinds of phenomena to which culture draws attention, and to humbly, incrementally, illuminate them.

\section{$\underline{\text { References }}$}

Almond, Gabriel A. and Sidney Verba (1963) Civic Culture: Political Attitudes and Democracy in Five Nations Princeton, NJ: Princeton University Press

Appadurai, Arjun (2004) 'The capacity to aspire: culture and the terms of recognition', in Vijayendra Rao and Michael Walton (eds.) Culture and Public Action Palo Alto: Stanford University Press, pp. 59-84

Barron, Patrick, Rachael Diprose and Michael Woolcock (2011) Contesting Development: Participatory Projects and Local Conflict Dynamics in Indonesia New Haven: Yale University Press

Bayly, C. A. (2004) The Birth of the Modern World, 1780-1914: Global Connections and Comparisons Oxford: Blackwell

Benovil, Ivan (2012) “An overview of the Russian literature on ethnicity” Mimeo, World Bank

Brubaker, Rogers (2009) 'Ethnicity, race and nationalism' Annual Review of Sociology 35: 21-42

Chua, Amy (2011) Battle Hymn of the Tiger Mother New York: Penguin Press

Collier, David, Fernando Daniel Hidalgo and Andra Olivia Maciuceanu (2006) 'Essentially contested concepts: debates and applications' Journal of Political Ideologies 11(3): 211-46

Davis, Wade (2009) The Wayfinders: Why Ancient Wisdom Matters in a Modern World Toronto: House of Anansi Press

Dirks, Nicholas (2001) Castes of Mind: Colonialism and the Making of Modern India Princeton, NJ: Princeton University Press

Dudwick, Nora, Elizabeth Gomart and Alexandre Marc, with Kathleen Kuehnast (eds.) (2003) When Things Fall Apart: Qualitative Studies of Poverty in the Former Soviet Union Washington, DC: World Bank

Easterly, William and Ross Levine (1997) 'Africa's growth tragedy: policies and ethnic divisions' Quarterly Journal of Economics 112(4): 1203-1250 
Edgar, Adrienne Lynn (2004) Tribal Nation: The Making of Soviet Turkmenistan Princeton, NJ: Princeton University Press

Gallie, W.B. (1956) 'Essentially contested concepts' Proceedings of the Aristotelian Society 56: $167-98$

Gauri, Varun, Michael Woolcock and Deval Desai (2013) 'Intersubjective meaning and collective action in developing societies: theory, evidence and policy implications' Journal of Development Studies 49(1): 160-172

Goode, Judith and Edwin Eames (1996) 'An anthropological critique of the culture of poverty', in George Gmelch and Walter P. Zenner (eds.) Urban Life: Readings in Urban Anthropology Long Grove, IL: Waveland Press, pp. 405-417

Greif, Avner and Murat Iyigun (2013) 'Social organizations, violence, and modern growth' American Economic Review: Papers and Proceedings 103(3): 534-538

Harrison, Lawrence E. and Samuel P. Huntington (eds.) (2001) Culture Matters: How Values Shape Human Progress New York: Basic Books

Henrich, Joseph, Steven J. Heine and Ara Norenzayan (2010) 'The weirdest people in the world' Behavioral and Brain Sciences 33(2-3): 61-83

Henrich, Joseph, Robert Boyd, Samuel Bowles, Colin F. Camerer, Ernst Feyer and Herbert Gintis (eds.) (2004) Foundations of Human Sociality: Economic Experiments and Ethnographic Evidence from Fifteen Small-Scale Societies New York: Oxford University Press

Hoff, Karla and Priyanka Pandey (2006) 'Discrimination, social identity, and durable inequalities’ American Economic Review 96(2): 206-211

Hoff, Karla, Mayuresh Kshetramade and Ernst Feyer (2011) 'Caste and punishment: the legacy of caste culture in norm enforcement' Economic Journal 121(556): F449-475

Huntington, Samuel P. (1996) The Clash of Civilizations and the Remaking of World Order New York: Simon and Schuster

Inglehart, Ronald (1997) Modernization and Postmodernization: Cultural, Economic and Political Change in 43 Societies Princeton, NJ: Princeton University Press

Inglehart, Ronald and Christian Welzel (2005) Modernization, Cultural Change, and Democracy: The Human Development Sequence New York: Cambridge University Press

Inkeles, Alex (1975) Becoming Modern: Individual Change in Six Developing Countries New York: Wiley 
Jha, Saumitra (2007) 'Maintaining peace across ethnic lines: new lessons from the past' Economics of Peace and Security Journal 2(2): 81-93

Jung, Courtney (2008) 'Race, ethnicity, religion', in Robert E. Goodin and Charles Tilly (eds.) Handbook of Contextual Political Analysis New York: Oxford University Press, pp. 360-375

Kalyvas, Stathis (2006) The Logic of Violence in Civil War New York: Cambridge University Press

Lamont, Michele (2000) The Dignity of Working Men: Morality and the Boundaries of Race, Class and Immigration Cambridge, MA: Harvard University Press

Landes, David (1999) The Wealth and Poverty of Nations: Why Some are So Rich and Some are So Poor New York: Norton

Lewis, Oscar (1959) Five Families: Mexican Case Studies in the Culture of Poverty New York: Basic Books

Mamdani, Mamood (1996) Citizen and Subject: Contemporary Africa and the Legacy of Late Colonialism Princeton, NJ: Princeton University Press

Marx, Anthony (1998) Making Race and Nation: A Comparison of South Africa, the United States and Brazil New York: Cambridge University Press

McGovern, Mike (2011) 'Popular development economics: an anthropologist among the Mandarins' Perspectives on Politics 9(2): 345-355

Mohan, Brij (2011) Development, Culture of Poverty and Social Policy New York: Palgrave Macmillan

Moore, Mick (1997) 'Societies, polities and capitalists in developing countries: a literature survey' Journal of Development Studies 33(3): 287-363

Murray, Charles (1994) Losing Ground: American Social Policy, 1950-1980 New York: Basic Books

Patterson, Orlando (2006) 'A poverty of the mind' New York Times, March 26

Posner, Daniel (2004) 'The political salience of cultural difference: Why Chewas and Tumbukas are allies in Zambia and adversaries in Malawi' American Political Science Review 98(4): 529545

Prasad, Chandra Bhan, D. Shyam Babu, Devesh Kapur and Lant Pritchett (2010) 'Rethinking inequality: Dalits in Uttar Pradesh in the market reform era' Economic and Political Weekly 45(35): 39-49 
Rao, Vijayendra (2008) 'Symbolic public goods and the coordination of collective action: a comparison of local development in India and Indonesia', in Pranab Bardhan and Isha Ray (eds.) The Contested Commons: Conversations Between Economists and Anthropologists New York: Wiley-Blackwell, pp. 168-86.

Rao, Vijayendra and Michael Walton (eds.) (2004) Culture and Public Action Palo Alto: Stanford University Press

Small, Mario (2004) Villa Victoria: The Transformation of Social Capital in a Boston Barrio Chicago: University of Chicago Press

Small, Mario Louis, David J. Harding and Michele Lamont (2010) 'Reconsidering culture and poverty' Annals of the American Academy of Political and Social Science 629(1): 6-27

Steele, Claude M. and Joshua Aronson (1995) 'Stereotype threat and the intellectual test performance of African Americans' Journal of Personality and Social Psychology 69(5): 797811

Swidler, Ann (1986) 'Culture in action: symbols and strategies' American Sociological Review 51(2): $273-286$

Szreter, Simon (2007) 'The rights of registration: development, identity registration, and social security—a historical perspective' World Development 35(1): 67-86

Tilly, Charles (1998) Durable Inequality Berkeley and Los Angeles: University of California Press

Tishkov, Valery A. (1997) Ethnicity, Nationalism and Conflict in and after the Soviet Union: The Mind Aflame Geneva: United Nations Research Institute on Social Development

Varshney, Ashutosh (2002) Ethnic Conflict and Civic Life: Hindus and Muslims in India New Haven: Yale University Press

Wadeen, Lisa (2002) 'Conceptualizing culture: possibilities for political science' American Political Science Review 96(4): 713-728

Weber, Eugen (1976) Peasants into Frenchman: The Modernization of Rural France, 1870-1914 Palo Alto: Stanford University Press

Wimmer, Andeas (2008) 'The making and unmaking of ethnic boundaries: a multilevel process theory' American Journal of Sociology 113(4): 970-1022

Woolcock, Michael (2009) 'The next ten years in development studies: from modernization to multiple modernities, in theory and practice' European Journal of Development Research 21(1): 4-9 
Woolcock, Michael (2010) 'The rise and routinization of social capital, 1988-2008' Annual Review of Political Science 13: 469-87

Woolcock, Michael (2013) 'Using case studies to explore the external validity of complex development interventions' Evaluation 19(3): 229-248 